\title{
REVIEW
}

\section{New laboratory predictive tools in deep neck space infections}

\author{
Nuovi indicatori biochimici predittivi di infezioni suppurative cervicali

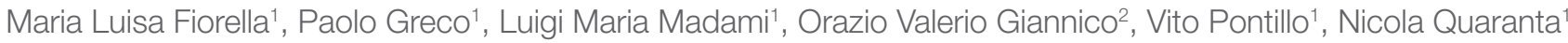 \\ 1 Unit of Otorhinolaryngology, Department of Biomedical Sciences, Neurosciences and Sense Organs, University of Bari, Italy; \\ 2 Section of Hygiene, Department of Biomedical Sciences and Human Oncology, University of Bari "Aldo Moro", Bari, Italy
}

\begin{abstract}
SUMMARY
Introduction. Deep neck space infections (DNSIs) are a group of infective suppurative diseases involving deep neck spaces and cervical fascia. Necrotising and septic evolutions are rare, but severe complications can dramatically affect the prognosis and should be promptly managed. Clinical examination often has low sensitivity, although instrumental diagnosis may delay te treatment. We investigated two laboratory tools, LRINEC (Laboratory Risk Indicator for the Necrotizing fasciitis) and NLR (neutrophil to lymphocyte ratio), in the expectation to find a rapidly available predictive indicator that may help in distinguishing necrotising complications and/or systemic septic involvement.

Methods. A retrospective observational cohort study was performed on 118 patients who had underwent surgical treatment for DNSIs at our Surgical Unit. LRINEC, NLR and the product LRINEC $x$ NLR were calculated.

Results. Statistical analysis showed that these scores may have utility in rapidly predicting the risk of necrotising fasciitis and systemic involvement at an early diagnostic stage.

Conclusions. Further studies with a larger cohort may be necessary in order to increase the sensitivity and specificity.
\end{abstract}

KEY WORDS: LRINEC, NLR, necrotizing fasciitis, sepsis, neck

\section{RIASSUNTO}

Introduzione. Le infezioni suppurative del collo sono un eterogeneo gruppo di patologie a carico degli spazi profondi del collo e delle fasce cervicali. Al suo interno meritano particolare attenzione le temibili fasciti necrotizzanti, caratterizzate dall'elevato tasso di mortalità e di compromissione settica. Risulta pertanto indispensabile una loro pronta diagnosi e un altrettanto tempestivo trattamento. La semeiologia clinica risulta spesso poco sensibile, mentre l'esame TC comporta un inevitabile ritardo nella presa in carico terapeutica. Abbiamo quindi valutato l'applicabilità di due indicatori basati unicamente su parametri laboratoristici, quindi rapidamente disponibili: LRINEC score e NLR ratio.

Metodi. Abbiamo condotto uno studio retrospettivo su 118 pazienti che erano stati sottoposti a drenaggio chirurgico di ascesso cervicale clo la nostra U.O., calcolando per ciascuno di essi LRINEC, NLR e il loro prodotto di moltiplicazione LRINEC x NLR.

Risultati. L'analisi statistica dimostra un loro possibile ruolo nella diagnosi tempestiva delle fasciti necrotizzanti elo delle loro complicanze settiche.

Conclusioni. Ulteriori studi con una maggiore numerosità campionaria potrebbero essere necessari per rafforzare sensibilità e specificità di tali score.

PAROLE CHIAVE: LRINEC, NLR, fasciti necrotizzanti, sepsi, cervicali

\section{Introduction}

Deep neck space infections (DNSIs) are a group of infective suppurative diseases involving deep neck spaces. They may occur at any age, although the mean age of onset is 49.5 years ${ }^{1}$.

DNSI usually occur in patients affected by multiple comorbidities; in par-
Received: April 9, 2020

Accepted: May 20, 2020

\author{
Correspondence \\ Paolo Greco \\ Unit of Otorhinolaryngology, Department of Bio- \\ medical Sciences, Neurosciences and Sense Organs, \\ University of Bari, piazza Giulio Cesare 11, 70124 \\ Bari, Italy \\ Tel. +39080 5593524 \\ E-mail: pao3greco@hotmail.it
}

Funding

None.

\section{Conflict of interest}

The Authors declare no conflict of interest.

How to cite this article: Fiorella ML, Greco P, Madami LM, et al. New laboratory predictive tools in deep neck space infections.Acta Otorhinolaryngol Ital 2020;40:332-337. https://doi. org/10.14639/0392-100X-N0790

() Società Italiana di Otorinolaringoiatria e Chirurgia Cervico-Facciale

\section{(c) (1) $(2)$}

This is an open access article distributed in accordance with the CC-BY-NC-ND (Creative Commons Attribution-NonCommercial-NoDerivatives 4.0 International) license. The article can be used by giving appropriate credit and mentioning the license, but only for non-commercial purposes and only in the original version. For further information: https:// creativecommons.org/licenses/by-nc-nd/4.0/deed.en 
ticular, diabetes may raise the risk of infection as a consequence of immunological alterations or secondary microangiopathy ${ }^{2}$.

Dental and oropharyngeal infections are the most common source of DNSI ${ }^{3,4}$, even if in a fourth of cases a defined trigger cannot be found ${ }^{5}$. Submandibular (36.26\%) and sublingual spaces (13\%) are the most frequent localisations followed by the para-pharyngeal (12\%) and retropharyngeal spaces $(3 \%)^{5}$.

The isolated microbes in DNSIs reflect the normal flora of the upper respiratory and digestive tract, with a strong prevalence of Gram+ bacteria (Streptococcus viridans $41.5 \%$, Staphylococcus aureus 20.7\%) ${ }^{5}$. The presence of Gram- germs (Pseudomonas aeruginosa 4.07\%, Klebsiella pneumonia $1.48 \%)^{6}$ is more frequently related to diabetic comorbidity ${ }^{2}$. Anaerobic bacteria (Prevotella 4\%, Fusobacterium $5 \%)^{7}$ have been demonstrated to play an important role in the development of cervical necrotising fasciitis $(\mathrm{CNF})^{7,8}$ due to the production of specific enzymes involved in the necrotising process ${ }^{8}$. Bacterial cultures can be polymicrobial in $20.8 \%{ }^{5}$ of cases and negative in $10.74 \%{ }^{6}$ of patients, probably due to the wide use of prehospitalisation antibiotic therapy or to technical difficulty in isolating anaerobic pathogens ${ }^{9,10}$.

Especially when involving para- and retro- pharyngeal spaces, DNSI may extend by continuity and contiguity to the mediastinal and thoracic spaces. Some authors have proposed the acronym DNM (descending necrotising mediastinitis) to define a necrotising mediastinitis arising as result of the secondary spread of a CNF (cervical necrotising fasciitis) ${ }^{7}$.

CNF, DNM and systemic septic involvement are potential life-threatening complications of DNSIs, hence it is important to have a reliable tool that allows a prompt detection of these complications.

Clinical examination allows identification of the typical clinical signs and symptoms of CNF (e.g. crackling palpation, brownish or hyperaemic skin and cutaneous fistula), but has low sensitivity $(67 \%){ }^{11}$; imaging techniques such as CT can be useful, but can delay treatment.

The aim of this study was to evaluate the role of two wellknown laboratory tools as predictive factors of DNSI complications such as CNF and sepsis.

The "Laboratory Risk Indicator for NECrotizing fasciitis" score (LRINEC) ${ }^{12}$ was first proposed by Wong et al. ${ }^{12}$ in order to promptly identify a necrotising complication in case of suppurative infections, not strictly localised in the cervical region. On the other hand, the neutrophil to lymphocyte ratio (NLR) has been proposed for its diagnostic and prognostic role in the early and late phases of the septic process ${ }^{13}$. The present study aims to demonstrate the utility of these indicators as predictive factors that may help in detecting CNFs or systemic involvement in course of DNSIs.

\section{Materials and methods}

A retrospective observational cohort study was performed on 118 patients who underwent surgical treatment for DNSIs at our Surgical Unit in the period between February 2008 and February 2018. Cases of peritonsillar abscess treated by transoral incision without cervical drainage were not included. Informed consent for surgery was obtained from all patients before surgery, which was performed within 48 hours after admission in all cases. All procedures were in accordance with the ethical standards of the institutional research committee and with the 1964 Helsinki Declaration and its later amendments or comparable ethical standards. Our Ethics Committee was informed of the retrospective data collection.

Each patient was submitted at admission to clinical examination and laboratory tests, including CBC (complete blood count), electrolytes, glycaemia, coagulation tests, liver and kidney functional tests and inflammatory markers (CPR, C-reactive protein and ESR, erythrocyte sedimentation rate). A neck and chest $\mathrm{CT}$ was performed in all cases with the purpose of finding the potential focus of infection and evaluate the extension of the suppurative process.

LRINEC and NLR scores were then calculated; furthermore, in order to reinforce the predictive power of our analysis, we proposed an additive indicator, the product between both the aforementioned scores (LRINEC x NLR).

LRINEC takes into account 6 laboratory values, assigning a specific score to each of them, as reported in Table I.

NLR is calculated as the ratio between neutrophil and lymphocyte percentages at $\mathrm{CBC}$.

LRINEC score, and consequently the product between NLR and LRINEC, was obtained only for a subgroup of 90 patients, since CRP was not routinely tested in our department pre-operatively.

Two outcomes were chosen: occurrence of CNF $(n=12 / 118)$ and sepsis. Detection of gas bubbles detection at CT and intraoperative finding of necrosis in patients affected by CNF. Septic systemic involvement was defined on the basis of the "The Third International Consensus Definitions for Sepsis and Septic Shock (Sepsis-3)" ${ }^{14}$. According to this, sepsis can be rapidly identified in non-intensive care settings using a new bedside clinical score termed quickSOFA (qSOFA), when at least 2 of the following clinical criteria are met:

- respiratory rate of 22/min or greater;

- altered mentation;

- systolic blood pressure of $100 \mathrm{~mm} \mathrm{Hg}$ or less. 
Table I. LRINEC score calculating model.

\begin{tabular}{lc} 
Variable, Unit & Score \\
C-reactive protein (CRP), mg/L & \\
$<150$ & 0 \\
$\geq 150$ & 4 \\
Haemoglobin, g/dL & \\
$>13.5$ & 0 \\
$11-13.5$ & 1 \\
$<11$ & 2 \\
Total white cell count, per mm ${ }^{3}$ & \\
$<15$ & 0 \\
$15-25$ & 1 \\
$>25$ & 2 \\
Sodium, mmol/L & \\
$\geq 135$ & 0 \\
$<135$ & 2 \\
Creatinine, $\mu \mathrm{mol} / \mathrm{L}$ & \\
$\leq 141$ & 0 \\
$>141$ & 2 \\
Glucose, $\mathrm{mg} / \mathrm{dL}$ & \\
$\leq 180$ & 0 \\
$>180$ & 1 \\
\hline
\end{tabular}

Septic shock is defined as a subset of sepsis in which a vasopressor is required to maintain a mean arterial pressure of $65 \mathrm{~mm} \mathrm{Hg}$ or greater and serum lactate level greater than $2 \mathrm{mmol} / \mathrm{L}$ (> $18 \mathrm{mg} / \mathrm{dL}$ ) in the absence of hypovolaemia ${ }^{14}$.

In accordance with these criteria, we identified 53 patients without sepsis, 52 with sepsis and 13 with septic shock.

\section{Statistical analysis}

Statistical analysis was performed using R 3.5.1. Statistical significance was reached with a $\mathrm{P}<0.05$. Categorical variables were reported as absolute and relative frequencies. Numerical variables were reported as median and IQR and compared through Wilcoxon and Kruskall Wallis rank sum test in order to account for non-normality (evaluated through Shapiro-Wilk test) and heteroscedasticity (evaluated through Bartlett test). Post-hoc analysis was performed through pairwise Wilcoxon rank sum test with Benjamini-Hochberg correction (false discovery rate).

Six ROC curves were then fitted for the three scores (LRINEC, NLR e LRINEC $\times$ NLR) and for the two outcomes (CNF and Sepsis Score), with the estimation of AUC (area under the curve), optimal cut-off, sensibility, specificity, positive and negative predictive value.

\section{Results}

118 patients underwent a surgical intervention for DNSIs between February 2008 and February 2018 in our Unit: 73 males (61.86\%) and 45 females (38.13\%) with a mean age of 48.39 years (range 2-83 years).

Table II reports the suspected foci of infection in our cohort. In $43.22 \%$ of cases the source was unknown as reported by other authors ${ }^{15}$. Dental infection was the most common cause occurring in a third of cases.

In Table II, the anatomical localisations of DNSIs in our series are reported. The submandibular region and the parapharyngeal space were involved in almost $50 \%$ of all cases, while multiple localisations occurred in 24 cases $(20 \%)$. In 4 cases $(3.4 \%)$, a mediastinal extension was evident.

Seventy patients $(59.32 \%)$ presented at least one major comorbidity (Tab. II), mostly hypertension (21.19\%) and

Table II. Clinical findings in our series.

\begin{tabular}{lcc} 
Sources of infection & N & $\%$ \\
Unknown & 51 & 43.2 \\
Odontogenic & 33 & 27.9 \\
Recurrent tonsillitis & 11 & 9.3 \\
Sialolithiasis & 8 & 6.8 \\
Previous neck procedures (FNAB/surgery) & 4 & 3.4 \\
Neck cysts & 3 & 2.5 \\
Lymphadenopathy & 3 & 2.5 \\
Mastoiditis & 2 & 1.7 \\
Other & 3 & 2.5 \\
Sites of infection & $\mathbf{N}$ & $\%$ \\
Submandibular & 34 & 28.81 \\
Parapharyngeal & 24 & 20.34 \\
Parotid space & 13 & 11.02 \\
Oral pelvis/base of tongue & 5 & 4.237 \\
Retropharyngeal & 3 & 2.542 \\
Multiple localisations & 24 & 20.34 \\
Other & 15 & 12.71 \\
Comorbidities & N & $\%$ \\
Hypertension & 25 & 21.19 \\
Diabetes & 16 & 13.56 \\
Cardiopathy & 10 & 8.475 \\
Autoimmune diseases & 5 & 4.237 \\
Endocrinopathy (except diabetes) & 4 & 3.39 \\
Nephropathy & 4 & 3.39 \\
Neoplasia & 3 & 2.542 \\
Chronic obstructive pulmonary disease (COPD) & 2.542 \\
None & 3 & 40.68 \\
\hline & & \\
\hline & 25 & \\
\hline
\end{tabular}


Table III. Kruskal-Wallis and Wilcoxon Tests.

\begin{tabular}{|c|c|c|c|c|c|}
\hline & & & $\begin{array}{l}\text { LRINEC } \\
\text { median (IQR) }\end{array}$ & $\begin{array}{c}\mathrm{NLR} \\
\text { median (IQR) }\end{array}$ & $\begin{array}{l}\text { NLR } x \text { LINREC } \\
\text { median (IQR) }\end{array}$ \\
\hline \multirow[t]{4}{*}{ Sepsis } & No sepsis & & 4.5 (3.3) & 7.0 (6.9) & $29.4(43.7)$ \\
\hline & Sepsis & & $5.0(3.0)$ & $10.3(11.3)$ & $59.2(71.7)$ \\
\hline & Septic shock & & $8.0(2.0)$ & $13.4(8.2)$ & $107.3(82.6)$ \\
\hline & & (Kruskal-Wallis Test) & $P=0.003$ & $P=0.001$ & $P<0.001$ \\
\hline \multirow[t]{3}{*}{ CNF } & Yes & & $8.0(3.5)$ & $15.0(17.5)$ & 86.3 (113.9) \\
\hline & No & & $5.0(3.5)$ & $9.2(9.5)$ & $39.2(72.5)$ \\
\hline & & (Wilcoxon Test) & $P=0.020$ & $P=0.041$ & $P=0.010$ \\
\hline
\end{tabular}

diabetes $(13.56 \%)$. In 11 cases $(9.32 \%)$, multiple comorbidities were found.

Surgical treatment, consisting in cervical incision with abscess drainage and cervical fascia/spaces debridement and rinsing, was performed in all cases. In 42 cases (35.59\%) the submandibular gland was removed; 4 patients $(3.39 \%)$ presented suppurative mediastinitis, thus necessitating thoracic drainage; tracheotomy was performed in 21 patients (17.79\%). Twenty-four patients $(20.33 \%)$ needed intensive care. The survival rate in our series was 98.3\%: 2 patients died for severe respiratory and systemic complications.

In Table III, LRINEC, NLR and LRINEC $x$ NLR values are reported in relation to sepsis and occurrence of CNF. Statistical analysis showed significantly higher values of LRINEC, NLR and NLR $x$ LRINEC in case of severe septic involvement (septic shock $>$ sepsis $>$ no sepsis) and CNF.

Pairwise comparison (Tab. IV) demonstrated a potential utility of LRINEC and NLR $x$ LRINEC in discriminating sepsis from septic shock.

ROC curves (Tab. V) show for both the considered outcomes (sepsis and CNF) the performances of the three scores, with acceptable values of AUC (between 0.6 and $0.8)$.

\section{Discussion}

Neck spaces are bordered by cervical fascia which represent, rather than an obstacle, a possible route of spreading for suppurative processes. For this reason, it is important to consider the possible dissemination of DNSIs, especially when evolving to CNF, to regions such as the mediastinum and thorax. In addition, the significant risk of systemic inflammatory involvement should not be ignored. Septic presentation in case of DNSIs has been frequently described by several authors ${ }^{4,16}$, especially in case of CNF. Thus, this condition must be considered as a challenging race against time, since only early diagnosis allows welltimed and adequate medical and surgical treatment. In fact, delayed diagnosis is considered to be one of the main pre-
Table IV. Pairwise comparison for Sepsis Score.

\begin{tabular}{lc} 
Wilcoxon rank sum test & P-value \\
LRINEC & \\
No Sepsis / Sepsis & 0.039 \\
No Sepsis / Septic shock & 0.004 \\
Sepsis / Septic shock & 0.039 \\
NLR & \\
No Sepsis / Sepsis & 0.011 \\
No Sepsis / Septic shock & 0.005 \\
Sepsis / Septic shock & 0.203 \\
NLRxLRINEC & \\
No Sepsis / Sepsis & 0.011 \\
No Sepsis / Septic shock & $<0.001$ \\
Sepsis / Septic shock & 0.034 \\
\hline
\end{tabular}

dictors of mortality and morbidity for DNSIs ${ }^{8}$, particularly in case of CNF.

CNF represent only $3.5 \%{ }^{15}$ of total DNSIs, but they dramatically affect the prognosis of these patients, with a mortality rate of $7-22 \%$, increasing to $41 \%$ in case of thoracic involvement and up to $64 \%$ if associated with DNM and septic complications ${ }^{17}$. This wide range is probably explained by the fact that early diagnosis requires relevant diagnostic instruments, not always available in poor resource countries, where the prognosis is obviously worse ${ }^{10}$. Hence, it has been stated that prompt diagnosis and surgical treatment within 12 hours ${ }^{8,18}$ from admission are strongly advisable in order to lower the mortality rate. Clinical signs of necrosis alone have been demonstrated to have a low sensitivity $(67 \%)$ in detecting $\mathrm{CNF}^{11}$. On the contrary, CT scan is a sensitive (79\%) and specific $(94 \%)$ tool ${ }^{15,19}$, but not always available in short time frames, especially in poorer countries. For this reason, the use of short-term laboratory predictors must be investigated in order to allow prompt diagnosis.

According to Wong et al. ${ }^{12}$, the risk of developing necrotising fasciitis is distinguishable on the basis of LRINEC in:

- low risk (probability less than 50\%) for LRINEC-score 5; 
- medium risk (probability of 50-75\%) for LRINEC-score between 6 and 7 ;

- high risk (probability more than $75 \%$ ) for LRINECscore $\geq 8$.

The Wong et al. ${ }^{12}$ model considers necrotising soft tissue infections in general and CNF was only minimally represented in their cohort. In their publication, Wong et al. demonstrated LRINEC score to be significantly associated with the risk of necrotising fasciitis.

Thomas et al. ${ }^{15}$ were the first to propose the application of LRINEC score to CNF, still achieving discouraging results. Sensitivity and specificity were, respectively, of $56 \%$ and $60 \%$ in case of value $\geq 6$ (medium risk according to Wong's model), $22 \%$ and $90 \%$ in case of value $\geq 8$ (high risk according to Wong). Sandner et al. ${ }^{19}$ found $94 \%$ sensitivity and $94 \%$ specificity in case of LRINEC score $\geq 6$, with a positive predictive value of 0.29 . They concluded that LRINEC score is a useful method to identify CNF cases early, especially in consideration of the easy availability of its parameters, even at an early stage.

In our analysis, we proposed another optimal cut-off, with a sensitivity of $54.5 \%$ and a specificity of $84.8 \%$ in detecting CNF for LRINEC score $\geq 7$ (Tab. V). Additionally, we have investigated the utility of this score in predicting the severity of systemic involvement. A cut-off of 6 was set to detect sepsis, but low sensitivity and specificity were found (respectively $42.6 \%$ and $86.1 \%$ ) (Tab. V).

Another indicator with proven clinical value in case of infection is NLR. It has been used as inflammation marker in several diseases, such as myocardial infarction ${ }^{20}$, psoriasis $^{21}$, gastritis ${ }^{22}$ and gangrenous appendicitis ${ }^{23}$. Baglam ${ }^{24}$ was the first to apply NLR as predictive factor for DNSIs, especially when occurring as a complication of acute bacterial tonsillitis in pediatric patients. An NLR cut-off of 5.4 was set to predict the risk of DNSI in these patients, with a sensitivity of $96 \%$ and a specificity of $83 \%$ (positive predictive value of $85 \%$ and negative predictive value of
95.4\%). In our study, we tried to find an application of this score as a predictor of the risk of CNF and sepsis, similarly to what was explained above for the LRINEC score. We found sensitivity and specificity values, respectively, of $50 \%$ and $84.9 \%$ (cut-off 17.5 ) in discriminating the risk of CNF and of $74.2 \%$ and $61.5 \%$ (cut-off 8.2 ) in predicting systemic septic involvement (Tab. V).

Based on the these first disappointing results, in accordance with other authors ${ }^{25}$, we proposed a new score, LRINEC $x$ NLR (multiplication of the above-mentioned scores), which was demonstrated to have acceptable sensitivity (90.9\% with a cut-off of 43.5 ) in discriminating the risk of CNF (Tab. V).

Nevertheless, LRINEC, NLR and LRINEC x NLR significantly differed depending on sepsis and the presence of necrotising phenomena, as demonstrated by our analysis. The research of new optimal cut-offs or the implementation by the mean of correction factors may represent a line of development for future perspectives, with the aim of increasing the sensitivity and specificity of these scores.

\section{Conclusions}

Septic and necrotising complications rarely occur in patients suffering from a head-neck suppurative infection, but enormously affect prognosis. Correct diagnosis is undoubtedly based on clinical presentation and instrumental techniques (CT), but laboratory markers must be taken into consideration as a prompt and valid aid. For this reason, we propose the use of LRINEC, NLR and LRINEC $x$ NLR scores as predictive tools to early evaluate septic complications and the risk of CNF in the course of DNSIs. As confirmed by our analysis, even though with a sensitivity and specificity values that were not encouraging, perhaps due to the poor number of our cohort, these scores may have utility in discriminating these potential life-threatening conditions. Further studies on a larger cohort may be helpful in

Table V. ROC indicators.

\begin{tabular}{|c|c|c|c|c|c|c|}
\hline \multicolumn{7}{|c|}{ Discriminating septic involvement (sepsis/septic shock) } \\
\hline Test & AUC & Cut-off & Sens. & Spec. & $\mathrm{PV}+$ & PV- \\
\hline LRINEC & 0.672 & 7.0 & 42.6 & 86.1 & 82.1 & 50.0 \\
\hline NLR & 0.679 & 8.2 & 74.2 & 61.5 & 71.0 & 65.3 \\
\hline NLRxLRINEC & 0.716 & 30.4 & 81.5 & 52.8 & 72.1 & 65.5 \\
\hline \multicolumn{7}{|c|}{ Discriminating CNF } \\
\hline Test & AUC & Cut-off & Sens. & Spec. & $\mathrm{PV}+$ & PV- \\
\hline LRINEC & 0.716 & 7.0 & 54.5 & 84.8 & 6.9 & 66.7 \\
\hline NLR & 0.681 & 17.5 & 50.0 & 84.9 & 6.2 & 72.7 \\
\hline NLRxLRINEC & 0.742 & 43.5 & 90.9 & 59.5 & 2.1 & 76.2 \\
\hline
\end{tabular}


finding other implementations with the purpose of increasing the clinical use of these scores.

\section{Acknowledgements}

We thank the Medical Laboratory of our Hospital for performing blood tests. We are also immensely grateful to the 'Istituto di Igiene' of University of Bari for statistical analysis. We would also like to show our gratitude to the University of Bari for the support and for providing all scientific material for the research.

\section{References}

1 Huang TT, Liu TC, Chen PR, et al. Deep neck infection: analysis of 185 cases. Head Neck 2004;26:854-60. https://doi.org/10.1002/ hed.20014

2 Lin HT, Tsai CS, Chen YL, et al. Influence of diabetes mellitus on deep neck infection. J Laryngol Otol 2006;120:650-4. https://doi. org/10.1017/S0022215106001149

3 Koç A, Alakhras WM, Acipayam H, et al. Seven years of experience in 160 patients with deep neck infection. KBB Uygulamalari 2016;4:22-6. https://doi.org/10.5604/01.3001.0010.5315

4 Huang TT, Liu TC, Chen PR, et al. Deep neck infection: analysis of 185 cases. Head Neck 2004;26:854-60. https://doi.org/10.1002/ hed.20014

5 Velhonoja J, Lääveri M, Soukka T, et al. Deep neck space infections: an upward trend and changing characteristics. Eur Arch Otorhinolaryngol 2020;277:863-72. https://doi.org/10.1007/s00405-01905742-9.

6 Atishkumar B, Vijayalaxmi A, Pallavi K. Deep neck space infection - a retrospective study of 270 cases at tertiary care center. World J Otorhinolaryngol Head Neck Surg 2016;2:208-13. https://doi. org/10.1016/j.wjorl.2016.11.003

7 Karkas A, Chahine K, Schmerber S, et al. Optimal treatment of cervical necrotizing fasciitis associated with descending necrotizing mediastinitis. British J Surg 2010;97:609-15. https://doi.org/10.1002/ bjs. 6935

8 Muhammad JK, Almadani H, Al Hashemi BA, et al. The value of early intervention and a multidisciplinary approach in the management of necrotizing fasciitis of the neck and anterior mediastinum of odontogenic origin. J Oral Maxillofac Surg 2015;73:918-27. https:// doi.org/10.1016/j.joms.2014.12.021

9 Sethi DS, Stanley RE. Deep neck abscesses - changing trends. J Laryngol Otol 1994;108:138-43. https://doi.org/10.1017/ S0022215100126106

10 Fomete B, Agbara R, Osunde DO, et al. Cervicofacial infection in a Nigerian tertiary health institution a retrospective analysis of 77 cases. J Korean Assoc Oral Maxillofac Surg 2015;41:293-8. https:// doi.org/10.5125/jkaoms.2015.41.6.293

11 Goldstein EJC, Anaya DA, Dellinger EP. Necrotizing soft-tissue infection: diagnosis and management. Clin Infect Dis 2007;44:705-10. https://doi.org/10.1086/511638
12 Wong $\mathrm{CH}$, Khin LW, Heng KS, et al. The LRINEC (Laboratory Risk Indicator for Necrotizing Fasciitis) score: A tool for distinguishing necrotizing fasciitis from other soft tissue infections. Crit Care Med 2004;32:1535-41. https://doi.org/10.1097/01. ccm.0000129486.35458.7d

13 Kaushik R, Gupta M, Sharma M, et al. Diagnostic and prognostic role of neutrophil-to-lymphocyte ratio in early and late phase of sepsis. Indian J Crit Care Med 2018;22:660-3. https://doi.org/10.4103/ijccm. IJCCM_59_18.

14 Singer M, Deutschman CS, Seymour CW, et al. The Sepsis Definitions Task Force Members. The third international consensus definition for sepsis and septic shock (Sepsis-3). JAMA 2016;315:801-10. https://doi.org/10.1001/jama.2016.0287

15 Thomas AJ, Meyer TK. Retrospective evaluation of laboratory-based diagnostic tools for cervical necrotizing fasciitis. Laryngoscope 2012;122:2683-7. https://doi.org/10.1002/lary.23680

16 Qu L, Liang X, Jiang B, et al. Risk factors affecting the prognosis of descending necrotizing mediastinitis from odontogenic infection. J Oral Maxillofac Surg 2018;76:1207-15. https://doi.org/10.1016/j. joms.2017.12.007

17 Sarna T, Sengupta T, Miloro M, et al. Cervical nectrotizing fascitis with descending mediastinitis: literature review and case report. J Oral Maxillofac Surg 2012;70:1342-50. https://doi.org/10.1016/j. joms.2011.05.007

18 Cruz Toro P, Callejo Castillo A, Tornero Saltó J, et al. Cervical necrotizing fasciitis: Report of 6 cases and review of literature. Eur Ann Otorhinolaryngol Head Neck Dis 2014;131:357-9. https://doi. org/10.1016/j.anorl.2013.08.006

19 Sandner A, Moritz S, Unverzagt S, et al. Cervical necrotizing fasciitis the value of the laboratory risk indicator for necrotizing fasciitis score as an indicative parameter. J Oral Maxillofac Surg 2015;73:2319-33. https://doi.org/10.1016/j.jams.2015.05.035

20 Dogan M, Akyel A, Bilgin M, et al. Can admission neutrophil to lymphocyte ratio predict infarct-related artery patency in ST-segment elevation myocardial infarction. Clin Appl Thromb Hemost 2015;2:1726. https://doi.org/10.1177/1076029613515071

21 Sen BB, Rifaioglu EN, Ekiz O, et al. Neutrophil to lymphocyte ratio as a measure of systemic inflammation in psoriasis. Cutan Ocul Toxicol 2014;33:223-7. https://doi.org/10.3109/15569527.2013.834498

22 Farah R, Khamisy-Farah R, et al. Association of neutrophil to lymphocyte ratio with presence and severity of gastritis due to Helicobacter pylori infection. J Clin Lab Anal 2014;28:219-23. https://doi. org/10.1002/jcla.21669

23 Ishizuka M, Shimizu T, Kubota K. Neutrophil-to-lymphocyte ratio has a close association with gangrenous appendicitis in patients undergoing appendectomy. Int J Surg 2012;97:299-304. https://doi. org/10.9738/CC161.1

24 Baglam T, Binnetoglu A, Yumusakhuylu AC, et al. Predictive value of the neutrophil-to-lymphocyte ratio in patients with deep neck space infection secondary to acute bacterial tonsillitis. Int $\mathbf{J}$ Ped Otorhinolaryngol 2015;79:1421-4. https://doi.org/10.1016/j. ijporl.2015.06.016

25 Neeki MM, Dong F, Au C. Evaluating the laboratory risk indicator to differentiate cellulitis from necrotizing fasciitis in the emergency department. West J Em Med 2017;18: 684-9. https://doi.org/10.5811/ westjem.2017.3.33607 